\title{
Assessment of Eligibility to National Register of Historic Places Building 431
}

\author{
M. A. Sullivan, R. A. Ullrich
}

Lawrence Livermore National

May 7, 2003 Laboratory 
This document was prepared as an account of work sponsored by an agency of the United States Government. Neither the United States Government nor the University of California nor any of their employees, makes any warranty, express or implied, or assumes any legal liability or responsibility for the accuracy, completeness, or usefulness of any information, apparatus, product, or process disclosed, or represents that its use would not infringe privately owned rights. Reference herein to any specific commercial product, process, or service by trade name, trademark, manufacturer, or otherwise, does not necessarily constitute or imply its endorsement, recommendation, or favoring by the United States Government or the University of California. The views and opinions of authors expressed herein do not necessarily state or reflect those of the United States Government or the University of California, and shall not be used for advertising or product endorsement purposes.

This work was performed under the auspices of the U.S. Department of Energy by University of California, Lawrence Livermore National Laboratory under Contract W7405-Eng-48. 


\title{
Assessment of Eligibility to National Register of Historic Places
} Building 431

Lawrence Livermore National Laboratory

\author{
Prepared by \\ Michael Anne Sullivan \\ with \\ Rebecca Ann Ullrich \\ Corporate History Program \\ Sandia National Laboratories
}

May 7, 2003 


\section{Executive Summary}

Lawrence Livermore National Laboratory (LLNL) proposes to demolish the original sections of Building 431 at its main site in Livermore, California. As this action will constitute an undertaking within the regulatory constraints of the National Historic Preservation Act, LLNL arranged for an assessment of the building's historic significance. This report provides a brief history of the magnetic fusion energy research activities housed in Building 431 and a historic assessment of the building.

The final recommendation of the report is that, although Building 431 housed some significant breakthroughs in accelerator technology and magnetic mirror plasma confinement, it lacks integrity for the periods of significance of those developments. It is, therefore, not eligible to the National Register of Historic Places. 


\section{Introduction}

This report assesses the historic significance of Lawrence Livermore National Laboratory's (LLNL) Building 431 within the requirements of the National Historic Preservation Act (NHPA). The report supports the U.S. Department of Energy's (DOE) efforts to evaluate potential historic properties at LLNL for NHPA compliance.

LLNL proposes to demolish the original sections of Building 431. This action represents a threat to the building and is, therefore, an undertaking as defined in the NHPA implementation guidance.

\subsection{LLNL}

LLNL is a U.S. DOE national laboratory operated by the University of California. ${ }^{1}$ LLNL's primary mission is the design and the maintenance of nuclear weapons for the U.S. stockpile. In addition to its function as a nuclear

\footnotetext{
${ }^{1}$ Lawrence Livermore National Laboratory was originally a branch of the University of California Radiation Laboratory. From its inception in 1952, the laboratory was identified as the University of California Radiation Laboratory, Livermore. In 1958, after the death of Ernest O. Lawrence, the laboratory name was changed to Lawrence Radiation Laboratory. In 1971, it became a separate entity from the Lawrence Berkeley Laboratory and was renamed the Lawrence Livermore Laboratory. In 1979, Congress designated it a national laboratory, and it became Lawrence Livermore National Laboratory. See University of California, Lawrence Livermore National Laboratory, Lawrence Livermore National Laboratory: A Concise History, 1952-2000, UCRL-TB-133100 (Livermore: University of California, Lawrence Livermore National Laboratory, 2000). For clarity, it will hereafter be referred to as Lawrence Livermore National Laboratory (LLNL), except when the discussion requires more precision for historical understanding.
}

weapons laboratory, LLNL conducts advanced research in physics, chemistry, environmental studies, computation, engineering, and biomedical science. ${ }^{2}$

LLNL is located forty miles east of San Francisco in Alameda County, California. The main site is situated on 821 acres and includes approximately 500 buildings and structures totaling 6,000,000 gross square feet. LLNL also maintains a 7,000-acre high explosives test area designated as Site 300. Located fifteen miles southeast of Livermore, in Alameda and San Joaquin counties, Site 300 includes approximately 200 buildings and structures totaling 400,000 gross square feet. ${ }^{3}$ Building 431 is located at the Livermore main site.

\subsection{Building 431}

Building 431, built in 1950, is a fourstory building with a high bay in the center of the structure. Offices and laboratories surround an open pit on two levels. The pit extends twenty feet below ground level and the high bay rises to the top of the roof for a total building height of 100 feet. A seven-foot-thick wallpart of which is made of numbered, concrete shielding blocks of varying sizes and part of which is seven-footthick poured concrete-surrounds this open pit area. The concrete shielding blocks are capped with concrete. The

\footnotetext{
${ }^{2}$ For an official description of LLNL's current mission and organization, see LLNL website, www.llnl.gov; and Charles R. Loeber, Building the Bombs: A History of the Nuclear Weapons Complex, SAND2002-0307P (Albuquerque: Sandia National Laboratories, 2002), 173. ${ }^{3}$ Paul McGuff, "Lawrence Livermore National Laboratory World War II and Later Historic Context and National Register Assessment: Scope of Work" (Livermore: Lawrence Livermore National Laboratory, 2002), 1.
} 
building is steel-framed and covered with sheet-metal-and-asbestos composite panels. It has a flat roof. There are windows on the first, second, and fourth floors on the north and south sides of the building. Building 431 is approximately 150,366 gross square feet. The exterior of Building 431 is shown in figure 1.

Building 431 was originally Building 57 of the Livermore Research Laboratory run by the California Research and Development Corporation (CR\&D), a subsidiary of the Standard Oil Company of California. From 1950 to 1954 , CR\&D and University of California Radiation Laboratory (UCRL) used the structure to house an AEC-sponsored project to develop fissionable materials for nuclear weapons.

In 1954, CR\&D transferred Building 57 to UCRL's new Livermore branch. It became Building 157 of the new UCRLLivermore nuclear weapons design laboratory. ${ }^{4}$ In 1967, in a laboratorywide re-numbering, it was designated Building 431. To avoid confusion, this report will refer to the structure as Building 431 throughout.

From 1954 to 1992, Building 431 housed successive generations of fusion research. The building has been extensively remodeled over the years to accommodate these experiments. In 1998, the last of the fusion research machines in the building was dismantled.

\footnotetext{
${ }^{4}$ Memorandum by Eustace Tombras, "Radiation Laboratory Building Numbers-Livermore Site," 27 May 1954, 434-900020, Box 761382, File 19, Donald Cooksey Administrative Files, Lawrence Berkeley Laboratory, 1954, Lawrence Berkeley National Laboratory Archives, Berkeley, California. Hereafter cited as LBNL Archives.
}

All experimental equipment has been removed from the main section of the building and it is currently empty. The building does contain an eighty-ton crane, seven-foot-thick concrete shielding blocks, a three-kilowatt cryogenic plant, a partial control room from the Microwave Tokamak Experiment (MTX), some of the power supplies, a large concrete shielding door on the first floor, and the outside platforms for the rough vacuum of the Mirror Fusion Test Facility Modification B (MFTF-B). The Experimental Test Accelerator (ETA), a weapons-related project, is also still active in the south wing of the building. Building 431, with the exception of the ETA, is slated for decontamination and decommissioning (D\&D) in the coming years. The ETA was installed in 1980; although it is not currently threatened, it will be included in this assessment.

\section{Methodology}

The following standard historical methodologies were used in conducting this assessment.

\subsection{Building Tour}

On March 18, 2003, Don Podesta, the engineering contact for Building 431, gave the authors of this report a building tour. The tour included the exterior, interior, and rooftop of Building 431. At that time, the authors also reviewed the building drawing files that remain in the facility.

\subsection{Documentary Research}

The authors conducted an extensive review of both published and manuscript primary sources pertaining to Building 431. Published scientific literature on controlled thermonuclear fusion proved particularly useful, as did documentary 
collections in the LLNL Archives, LLNL Reports Library, LLNL Plant Engineering Library, and the Lawrence Berkeley National Laboratory (LBNL) Archives.

The architectural drawings and floor plans of Building 431 provided information regarding construction history, building materials, architects and engineers, and the different activities that took place in the building over the years. Original research reports, photographs, facility manuals, safety reviews, equipment manuals, incident reports, and design proposals offered additional information regarding the type of activities undertaken in Building 431.

The authors also used primary documents to reconstruct the mission of Building 431 within the larger historical context of LLNL and the Cold War. Annual reports, development plans, memoranda from the Director's Office Administrative Files, informal historical overviews of LLNL, and articles from the various in-house publications of LLNL were particularly useful for this purpose.

\subsection{Secondary Literature Review}

To supplement the primary research, the authors conducted a search of the relevant history of science secondary literature on accelerators and controlled thermonuclear fusion research. A literature review of the historiography of the Cold War and post-World War II (WWII) science helped determine the relevant historic context to assist in the evaluation.

\section{Historic Context}

Determining if properties are eligible for the National Register of Historic Places requires the identification of the local, state, national, and/or international historic contexts that might give a property significance. ${ }^{5}$ In other words, it is necessary to determine which broader historical events, themes, or trends give a property meaning and importance.

\subsection{Local Context}

LLNL as a whole is significant in the context of the growth and development of both Livermore and California. However, it is unlikely that any individual building or set of structures at LLNL represents the laboratory's impact on either local or state history. Building 431 was never directly associated with the local community and has had no immediate impact upon its history. Local context will not be considered further within Building 431's historical assessment.

\subsection{Cold War Context}

The primary historic context for assessing the significance of LLNL buildings is the Cold War. The Cold War, although still a fairly recent event in U.S. history, has been widely recognized by both professional historians and cultural resource professionals as an event of exceptional significance within the nation's history. ${ }^{6}$

\footnotetext{
${ }^{5}$ U.S. Department of the Interior, National Park Service, Interagency Resource Division, National Register Bulletin 15: How to Apply the National Register Criteria for Evaluation (Washington, DC: GPO, 1991), 9.

${ }^{6}$ U.S. Department of Defense, Coming in from the Cold: Military Heritage in the Cold War: Report on the Department of Defense Legacy Cold War Project (Washington, DC: Department of Defense, 1994); Rebecca Ullrich, Sandia In the Cold War: A Statement of Historic Context for Sandia National Laboratories/New Mexico, draft (Albuquerque: Sandia National Laboratories, 2000), 9-10; and Kris Mitchell, Rhetoric to Reality: A Cold War Context
} 
The Cold War spanned the forty-five years from 1945 to 1989 and encompassed a series of events, policy decisions, and conflicts between the United States and the Soviet Union over the economic and political orientation of various countries in Europe, Asia, and the Middle East. In essence, the United States and the Soviet Union had incompatible and conflicting visions for the fate of the post-war world. The United States envisioned a world that closely mirrored its capitalist and democratic economic and political structure, while the Soviet Union hoped for a world that resembled its communist political and economic structure. ${ }^{7}$

The Cold War dominated almost every aspect of American life-diplomatic, military, social, economic, scientific, and political. Nevertheless, for the purposes of this report, only two aspects of Cold War history are relevant - the history of the arms race and the more general history of nuclear science.

LLNL was established as a direct response to U.S. policymakers' Cold War concern over the 1949 Soviet

Statement for the Pantex Plant, 1951-1991, draft (Amarillo: Pantex Plant, 2001).

${ }^{7}$ The literature on the Cold War is immense. Some good general studies include Walter LaFeber, America, Russia, and the Cold War, 1945-1985 (New York: Alfred A. Knopf, 1985); Martin McCauley, Russia, America, and the Cold War (New York: Longman, 1998); and Charles Morris, Iron Destinies, Lost Opportunities: A History of the Arms Race between the U.S. and the USSR, 1945-1987 (New York: Harper and Row, 1988). Studies exploring the relationship between Cold War policy and the nuclear arms race include Gregg Herken, Counsels of War (New York: Alfred A. Knopf, 1985); and Scott D. Sagan, Moving Targets: Nuclear Strategy and National Security (Princeton: Princeton University Press, 1989). detonation of its first nuclear device. In 1952, the Atomic Energy Commission (AEC) designated LLNL as a second nuclear weapons design laboratory. The core of LLNL's original mission was to develop a deliverable thermonuclear weapon and to support the Los Alamos National Laboratory (LANL) nuclear weapons design and testing programs. ${ }^{8}$ As LLNL's mission developed during the 1950s, it incorporated more general scientific nuclear research as part of the U.S. push to maintain scientific, nuclear, and technological superiority over the Soviet Union. Most of the buildings at LLNL were built during this decade.

LLNL's origins and mission place it within the context of the Cold War and, more specifically, within the context of the nuclear arms race and the technological and scientific advance of nuclear science.

Building 431 will be found historically significant to the extent that it reflects these specific Cold War legacies.

\subsection{Cold War Preservation Themes}

Within the broad historic context of the Cold War, the following themes and sub-themes represent LLNL's relationship and potential contribution to these larger events:

\footnotetext{
${ }^{8}$ Sybil Francis, "Warhead Politics: Livermore and the Competitive System of Nuclear Weapon Design," Ph.D. dissertation, Department of Political Science, Massachusetts Institute of Technology, 1995; and Peter Westwick, The National Labs: Science in an American System, 1947-1974 (Cambridge: Harvard University Press, 2003). Los Alamos National Laboratory (LANL) will be referred to throughout this report by its current name. Like LLNL it went through several name changes.
} 
- Nuclear Weapons Design

- Computing

- Nuclear Weapons Testing

- High Explosives Testing

- Nuclear Research

- Nuclear Physics Research

- Nuclear Chemistry Research

- Nuclear Materials Research

- Non-weapons Research

- Nuclear Energy Research

- Nuclear Propulsion Research

- Plowshare

- Biomedical Research

The LLNL Cold War preservation themes and sub-themes most relevant to the assessment of Building 431 are the theme of Nuclear Weapons Design, the sub-theme of Nuclear Physics Research within the theme of Nuclear Research, and the sub-theme of Nuclear Energy Research within the theme of Nonweapons Research.

Theme: Nuclear Weapons Design From 1950 to 1954, Nuclear Weapons Design represents the relevant preservation theme for Building 431's assessment. Building 431 was built after WWII to house a prototype accelerator designed to prove principles of largescale fissionable material production for the nuclear weapons program. This program was cancelled in 1954.

The theme of Nuclear Weapons Design again becomes relevant in 1980 when the ETA was installed in the south wing. The ETA was designed to study particle beams as a weapons application. This research is ongoing and has not yet had a noteworthy impact on weapons development. Therefore, Building 431 will not qualify for National Register consideration under this preservation theme during the time period 1980 to the present. Moreover, the south wing, where the current accelerator, the ETA II, is located is not currently threatened.

Theme: Nuclear Research;

Sub-theme: Nuclear Physics Research

From 1954 to 1958, the sub-theme of Nuclear Physics Research within the theme of Nuclear Research is relevant for the assessment of Building 431 . During these years, the building housed an accelerator used for pure physics research. The A-48 accelerator was used to measure $\mathrm{x}$-ray energies in the rare earth elements. A total of fifty $\mathrm{x}$-rays were made before the A-48 was dismantled. ${ }^{9}$ However, the A-48 accelerator research did not result in significant scientific breakthroughs or discoveries. Rather, it represents routine incremental scientific investigations. Therefore, Building 431 does not qualify for National Register consideration within this preservation sub-theme during the 1954 to 1958 time period.

The sub-theme of Nuclear Physics Research again becomes relevant from 1958 to 1973, when the Astron induction linear accelerator was in operation in Building 431. Although the Astron accelerator was designed for the fusion research program, it also contributed significantly to the development of particle accelerator research. Astron was a prototype for later induction linear accelerators. Therefore, the sub-theme of Nuclear Physics Research will be used for the assessment of Building 431 from 1957 to 1973.

\footnotetext{
${ }^{9}$ University of California Radiation Laboratory, Status Report: Fiscal Year 1958 (Berkeley and Livermore: University of California Radiation Laboratory, 1958), 76-77.
} 
Theme: Non-weapons Research; Sub-Theme: Nuclear Energy Research From 1954 to 1992, the primary mission of Building 431 was thermonuclear fusion research, which falls within the Cold War context preservation theme of Non-weapons Research, and the subtheme of Nuclear Energy Research. All the experiments that took place for this mission, and the equipment built for these experiments, had the goal of heating and containing plasma long enough for a thermonuclear reaction to take place. Many of the experiments in Building 431 contributed important information to the fusion research program. Therefore, the following discussion of Building 431's history will focus on these projects in some depth to determine if any of them are of historic significance.

\section{Building 431 History}

Both the construction and the program history of Building 431 are detailed within the narrative below.

\subsection{The Material Test Accelerator}

In 1950, CR\&D built Building 431 on the grounds of the decommissioned WWII Livermore Naval Air Station, to house the Material Test Accelerator (MTA). The MTA was a project conceived by E. O. Lawrence, director of UCRL, to produce fissionable materials (plutonium and tritium) in a gigantic linear accelerator. The accelerator would produce neutrons to transform useless tailings of uranium238 into the more easily fissionable plutonium-239. ${ }^{10}$

${ }^{10}$ Dan Wilkes, "The Most Fantastic Accelerator," Newsline Weekly Bulletin, 16 January 1980, 1-2; and "Lawrence and his Laboratory: Nuclear Science at Berkeley," $L B L$ News Magazine, Fall 1981, 62-75.
Lawrence proposed the building of three distinct machines for the MTA project: the Mark I, Mark II, and Mark III. The AEC initially supported all three projects in the tense Cold War atmosphere of the late 1940s. Building 431 housed the Mark I, a prototype 25 millionelectronvolts $(\mathrm{MeV})$ accelerator, with which Lawrence planned to demonstrate the feasibility of producing fissionable material in a linear accelerator. If the Mark I proved successful, then plans would proceed to construct the Mark II, a production plant with a $350-\mathrm{MeV}$ accelerator capable of producing a gram of neutrons a day. ${ }^{11}$ Lawrence also proposed the Mark III, a high-intensity $300-\mathrm{MeV}$ cyclotron that would provide an alternate source of neutrons. ${ }^{12}$

Construction of Building 431 began in June 1950. CR\&D built the massive vacuum tube for the Mark I accelerator first and then framed the building around it. The vacuum tube and frame of Building 431 are shown in figure 2. A series of interlocking, seven-foot-thick concrete blocks provided shielding around the Mark I accelerator. A structure of metal stairs and platforms surrounded the accelerator and the shielding blocks to allow scientists access to the machine on all levels. ${ }^{13}$

\footnotetext{
11 "Lawrence and his Laboratory," 64.

${ }^{12}$ Ibid., 70.

${ }^{13}$ Wilkes, "The Most Fantastic Accelerator," 2; "Livermore Research Laboratory Accelerator Building Cutaway Perspective," PLR-51-157O43J, Plant Engineering Library, Lawrence Livermore National Laboratory; and "Erection Diagram and Bolting Details, Accelerator Shielding, Accelerator Building, Plant \#3, Project X-1," PLR-51-157-047JF, Plant Engineering Library, Lawrence Livermore National Laboratory. LLNL Plant Engineering Library hereafter cited as PEL.
} 
The Mark I was the largest linear accelerator of its time. The vacuum chamber measured sixty feet in diameter and eighty-seven feet in length. Eighteen separate oscillators supplied eighteen megawatts of power to the chamber, each with an $\$ 8,000$ radio frequency tube built by RCA. The copper drift tubes weighed up to thirty tons each. Scientists and workers accessed the drift tubes by means of a standard-gauge railroad track made of manganesehardened copper that extended underneath the accelerator. ${ }^{14}$

In 1950, the AEC acquired a site in Weldon Springs, Missouri, for the Mark II facility but held off production until the Mark I had proven itself. From 1958 to 1966, the AEC used the Weldon Springs site to produce uranium and thorium. Lawrence also asked UCRL scientists to begin studies on the Mark III cyclotron. ${ }^{15}$ By 1951, they had demonstrated its feasibility on a onetenth scale-model electron accelerator. ${ }^{16}$

CR\&D engineers and scientists completed the Mark I in 1952. On May 19, 1952, the Mark I produced its first proton beam, albeit of marginal quality. Electrical discharges between the drift tubes shut down the accelerator for long periods of time. ${ }^{17}$

That same year, prospectors discovered rich uranium deposits in Colorado. As a result, the need for the MTA became less urgent. The AEC cancelled plans for

\footnotetext{
${ }^{14}$ Wilkes, "The Most Fantastic Accelerator," 2; and "Lawrence and his Laboratory," 69.

15 "Production Particle Accelerators," 11 April 1951, E. O. Lawrence Papers, Series 8, Reel 50, Frame 110999, Bancroft Library, University of California, Berkeley.

16 "Lawrence and his Laboratory," 71.

${ }^{17}$ Wilkes, "The Most Fantastic Accelerator," 2.
}

many of the MTA projects. In 1953, the accelerator in Building 431 was dismantled; the contract with CR\&D lapsed at the end of $1954 .^{18}$

Although the Mark I ran only a total of ten times, MTA scientists judged it a success because "[it] confirmed the possibility of holding a very high vacuum in a very large vessel, of maintaining the necessary potential gradient, and of introducing focusing magnets in the drift tubes." 19 The summary of the project stated that the Mark I effort had produced the largest heavy particle beam of any machine so far and developed the technology to build an even better one in the future.

Although the Mark I was dismantled in 1954, the MTA program retained the A48 accelerator on the first floor of Building 431. The A-48, originally part of the MTA program, was used for nuclear research problems. The A-48 effort was cancelled in 1958 and the accelerator relocated to UCRL-Berkeley.

\subsection{Project Sherwood}

As early as the 1950 s, scientists worried about the inevitable exhaustion of the world's supply of fossil fuel. One avenue scientists pursued was to replace costly sources of energy with fusion, which would rely on one of the world's cheapest elements - deuterium, a heavy hydrogen found abundantly in the ocean. $^{20}$

\footnotetext{
18 Ibid.

19 "Lawrence and his Laboratory," 69.

${ }^{20}$ University of California, Lawrence Livermore National Laboratory, 30 Years of Technical Excellence (Livermore: Lawrence Livermore National Laboratory, 1982), 32.
} 
In 1951, the AEC established Project Sherwood to explore the possibility of harnessing fusion for energy applications. The AEC funded work on Project Sherwood at multiple sites. LBNL, LANL, Oakridge National Laboratory (ORNL), the Naval Research Laboratory (NRL), New York University, Massachusetts Institute of Technology, Princeton University, and LLNL participated in the search for controlled nuclear fusion. ${ }^{21}$

The basic requirements established to produce and control fusion for energy were fourfold:

- To heat a small amount of fusion fuel until it combusts - at hundreds of millions of degrees.

- To confine the super-heated fuel in a chamber (without touching the walls) long enough for the fusion energy released to exceed its combustion temperature.

- To convert the energy released into electricity or heat.

- To replace the combusted fuel and remove the waste product. ${ }^{22}$

To meet these requirements, $\mathrm{AEC}$ scientists endeavored to develop a special magnetic field produced by magnetic coils that surrounded the fusion combustion chamber. The magnetic field prevented the superheated fuel, or plasma, from contacting the chamber. Several promising concepts were pursued, including the pinch, the stellerator, and the magnetic mirror. ${ }^{23}$

${ }^{21}$ Amasa S. Bishop, Project Sherwood: The U.S. Program in Controlled Fusion (Reading, Mass.: Addison-Wesley Publishing Inc., 1958), 20-21.

${ }^{22} 30$ Years of Technical Excellence, 32.

${ }^{23}$ Ibid.
The pinch-concept approach attempted to create a magnetic field from the internal, unidirectional currents of the plasma. The magnetic field constricted or pinched the plasma. LLNL, LBNL, and LANL all had pinch programs. ${ }^{24}$

The stellerator concept approach confined plasma in an endless tube shaped in a figure eight and employed an external magnetic field along the tube's axis. Princeton primarily pioneered this effort. $^{25}$

The magnetic mirror concept confined plasma in a straight tube with an external axis magnetic field. Mirrors were used to prevent the loss of particles from the ends of the tube. LLNL pioneered this method, although LANL, ORNL, and the NRL also eventually pursued this type of fusion research. ${ }^{26}$

\subsection{Early LLNL Magnetic Mirror Machines}

In 1952, LLNL scientists first began research on Project Sherwood in Building 212, the WWII navy drill hall. LLNL's Sherwood efforts primarily focused on the magnetic mirror concept. Several small model machines were initially built in Building 212 to study the feasibility of containing superheated plasma with magnetic mirrors. The Toy Top machine, one inch in diameter and twelve inches in length, succeeded in containing heated plasma several hundred microseconds. Table Top I, with a vacuum chamber six inches in diameter and seventy-two inches in

\footnotetext{
${ }^{24}$ Bishop, Project Sherwood, 20-21; and Samuel Glasstone and Ralph Loveberg, Controlled Thermonuclear Reactions: An Introduction to Theory and Experiment (Princeton, New Jersey: D. Van Nostrand Company Inc., 1960), 55.

${ }^{25}$ Bishop, Project Sherwood, 20-21.

${ }^{26}$ Ibid.
} 
length, had containment times even longer-reaching several milliseconds. Cucumber I, with a vacuum chamber eighteen inches in diameter, was the first machine to fully demonstrate the feasibility of the mirror confinement effect. ${ }^{27}$

In 1954, as the MTA project came to a close, Project Sherwood moved into Building 431. A three-phase construction plan created suitable office and laboratory space for mirror machines currently operating and under construction (Phase I), provided space for magnetic coil power and pulsed energy (Phase II), and provided space for the expansion of the program (Phase III). ${ }^{28}$

The proposed renovations to Building 431 made alterations to the structure to accommodate seven separate fusion research machines and their accompanying laboratories, control rooms, and shops. Phase I was completed by the time Sherwood moved into the building. Successive phases accommodated the expansion and alterations in the equipment and project plans.

Phase I made available approximately 25,000 square feet to Project Sherwood

${ }^{27}$ Alton L. Wilson to J. E. Armstrong, 6 October 1954, R. F. Post Collection, 90160, Box 001, Folder 21235, LLNL Archives; University of California Radiation Laboratory, "Preliminary Proposal Project Sherwood Facilities Building 157 Livermore," 22 December 1954, R. F. Post Collection, 90160, Box 001, Folder 21235, LLNL Archives; and R. F. Post, "Outline of UCRL Sherwood Experimental Program and Its Immediate Goals," 20 April 1955, R. F. Post Collection, 90614, Box 048, Folder 21523,

LLNL Archives.

28 "Preliminary Proposal Project Sherwood Facilities Building 157 Livermore," 5-6. experiments. On the first floor, Squash, a new and larger fusion machine than the Toy Top and the Table Top machines, was to be constructed and housed on the east side of the building and to the north of the center line outside of the pit areas. A machine shop was located in the far northeast corner of the building. Another large magnetic mirror machine was planned for the east end of the building south of the centerline. ${ }^{29}$

On the second floor, new space was added to accommodate light and medium laboratory work. ${ }^{30}$

On the north side of the third floor, rooms were added to house Toy Top, Table Top I, Table Top II, and their energy storage banks and other experimental equipment. On the south side of the third floor, rooms were added for several short-range experiments. ${ }^{31}$

Phase II provided for the extra power requirements necessary for the Sherwood program. A new condenser bank and a generator were purchased, and a 4,800-square-foot Butler-type building was erected to house them to the north of Building $431 .^{32}$

\footnotetext{
${ }^{29}$ Ibid., 6; and "Building 157 Project Sherwood First Floor Plan Phase I," L 157 A1003 A, 1954, R. F. Post Collection, 90160, Box 001, Folder 21235, LLNL Archives.

30 "Building 157 Project Sherwood Second Floor Plan Phase I," L 157 A1013 A, R. F. Post Collection, 90614, Box 048, Folder 21523, LLNL Archives.

31 "Preliminary Proposal Project Sherwood Facilities Building 157 Livermore," 6; and "Building 157 Project Sherwood Third Floor Plan Phase I," L 157 A1023 A, 1954, R. F. Post Collection, 90160, Box 001, Folder 21235, LLNL Archives.

32 "Preliminary Proposal Project Sherwood Facilities Building 157 Livermore," 6.
} 
Phase III provided space for the future expansion of Project Sherwood. To accomplish this, the concrete shielding was moved closer to the centerline; and decking was installed to cover the exposed pit on the first floor. These renovations made space for two additional laboratories. The first new laboratory was located on the north wall and would be used for the Albedo and the Cucumber I machines. The other laboratory was to occupy the space made available by moving the concrete blocks toward the centerline and would house Cucumber II and other mirror machines. $^{33}$

The new machines installed in Building 431-Table Top II and Cucumber IIwere part of the magnetic mirror program run by LLNL physicist Richard F. Post. The primary objective of these machines was to "create, heat, and control a high temperature plasma by means of externally generated magnetic fields." ${ }^{34}$ Each of these machines tackled the problem in a slightly different manner.

Toy Top II was the same size as Toy Top I, but it attained higher mirror fields. Squash, a larger version of Table Top with a vacuum chamber twelve inches in diameter and eighteen to twenty feet in length, never made it past the proposal stage. Cucumber II had a

${ }^{33}$ Ibid., 6-7; and "Building \#157 Project Sherwood First Floor Plan Phase III," L 157 Al003B, R. F. Post Collection, 90160, Box 001, Folder 21235, LLNL Archives.

34 "Controlled Thermonuclear Research at the University of California Lawrence Radiation Laboratory: A Review for the Atomic Energy Commission," 13 December 1960, R. F. Post Collection, 90606, Box 048, Folder 21523, LLNL Archives. vacuum tube eighteen inches in diameter. $^{35}$

In 1960, the Toy Top machine succeeded in heating and containing plasma in a mirror system for the first time at LLNL. The Toy Top machines were, therefore, chosen as the most likely model to succeed in the Sherwood project; and plans for a larger version were implemented. By 1963, the Toy Top machine required more space, and the latest version-Toy Top III or the $2 \mathrm{X}$ - was moved to Building 435 . $^{36}$

In 1961, Table Top II was completely rebuilt into Table Top III with greatly improved vacuum conditions and lengthened containment times -0.2 seconds. ${ }^{37}$ Table Top III remained a very flexible research machine for many years.

\subsection{Astron}

In 1958, after the removal of the A-48 accelerator, the next big fusion experiment installed in Building 431 was Astron. Astron was an entirely different approach to the problem of controlled thermonuclear fusion.

Astron was the brainchild of Nicholas Christofilos, an American physicist educated in Greece. In 1953, LLNL hired Christofilos to develop and implement his Astron fusion machine.

\footnotetext{
${ }^{35}$ R. F. Post, unpublished notes on Sherwood, n.d., R. F. Post Collection, 90614, Box 048, Folder 21523, LLNL Archives, 9; and Post, "Outline of UCRL Sherwood Experimental Program and Its Immediate Goals," 4-7.

36 "Sherwood Program Development," R. F. Post Collection, Box 260, Folder 2628, LLNL Archives, 1.

${ }^{37}$ Helen Black, "Sherwood," manuscript, Box 221, Folder 2123 Writings on Sherwood and Pluto History, LLNL Archives, 5-7.
} 
The idea behind Astron was to use an electronic accelerator to "accelerate electrons to relativistic energies for use in ... heating and containing hot plasmas. ${ }^{38}$ Christofilos spent three years working on the theoretical model of Astron before beginning work on the physical project in 1956. From 1957 to 1959, Christofilos developed the components of his machine. In 1958, installation of the Astron model began in Building $431 .{ }^{39}$ Astron was a multi-stage project. The initial components of the machine went into the northern portion of the pit area with a control room adjacent on the first floor. ${ }^{40}$

Modifications to the building continued over the next five-year period as additional parts of the machine were completed. The electron beam was started up in 1962 and achieved full power by 1963. In 1967 and 1969, two additional increments were added to the building on the south side to accommodate the electron accelerator. The completed Astron system consisted of a five-MeV, 200-amphere pulsed linear accelerator and a ninety-foot tube with external coils. ${ }^{41}$ The main chamber

38 “"'Astron' Linear Accelerator Goes on the Air," The Magnet, April 1963, 1, 9.

39 "Controlled Thermonuclear Research at the University of California Lawrence Radiation

Laboratory: A Review for the Atomic Energy Commission," 3.

${ }^{40}$ University of California Radiation Laboratory, "Construction Project Data Sheet," R. F. Post Collection, 21706, Box 023, Folder 90321 Construction and Alteration to Buildings 124, 157, and 131, LLNL Archives.

41 "Building 157 Astron 4 MEV Accelerator Facility Shielding Building Modifications/ Additions Architectural Partial Floor Plan (South)," PLA 1966-0431-003DA, PEL; “Astron Beam Research Experimental Facility Building 431/432 Building 431 Increment 4 Floor Plan," PLA 1968-0431-0011ED, PEL; and "“Astron' Linear Accelerator Goes on the Air," 1. of the Astron experiment is pictured in figure 3 .

The crux of the Astron research program was the E-layer, a cylindrical layer of electrons "moving in helical orbits in a magnetic field. $" 42$ If successful, the Elayer would create a second field within the orbits. These two fields would create the conditions necessary for the heating and containing of plasma long enough for a thermonuclear reaction to take place. $^{43}$

As early as 1962, the AEC, although initially supportive of the Astron project, began to withdraw its favor as the costs mounted and technical problems delayed progress. ${ }^{44}$ Nevertheless, LLNL managed to keep the program funded until 1973. Technical problems continued to plague the project; after the death of Christofilos in 1972, it was discontinued. In 1973, the Astron project was formally terminated. E-layers only half as powerful as needed to successfully meet Astron's goals were ever achieved. ${ }^{45}$ Nevertheless, the Astron experiment accumulated

\footnotetext{
${ }^{42}$ John Foster to Glenn Seaborg, 25 October 1962, Donald Cooksey, Administrative Files, Lawrence Berkeley Laboratory, 1962, Folder Sherwood Correspondence, LBNL Archives, 2. 43 “' Astron' Linear Accelerator Goes on the Air," 1.

${ }^{44}$ Foster to Seaborg, 25 October 1962; and Paul W. McDaniel to Edwin M. McMillan, 28 January 1963, Donald Cooksey, Administrative Files, Lawrence Berkeley Laboratory, 1963, Sherwood Project General Correspondence, LBNL Archives.

${ }^{45}$ Lawrence Livermore Laboratory, Controlled Thermonuclear Research Annual Report, UCRL50002-73 (Livermore: University of California Lawrence Livermore Laboratory, 1973), 1.
} 
information valuable to later projects in field-reversed mirror technology. ${ }^{46}$

\subsection{Pinch Program}

Building 431 also housed LLNL's experiments in the pinch concept of plasma confinement. In 1954, when Building 431 was first renovated for Project Sherwood, the Pinch Program acquired space for its experiments next to the larger magnetic mirror machines. ${ }^{47}$

Pinch research attempted to confine plasma in a closed structure in which the internal currents of plasma created the magnetic field. Early approaches to this method of plasma confinement included the toroidal stabilized pinch, the electron beam experiment, the linear pinch device, and the hard-core pinch experiment. $^{48}$

By 1960, the hard-core pinch experiment seemed the most likely to succeed, and plans proceeded to develop a machine called Levitron. Levitron had a toroidal shape, and a center ring levitated by the magnetic field structure that confined the plasma. After the first Levitron machine was successfully tested, a larger one was constructed in 1961. Levitron was rebuilt again in $1963 .{ }^{49}$

By 1965, substantial progress in hot plasma physics had been made on Levitron. Scientists studying the pinch concept had developed an understanding of various kinds of plasma instability

\footnotetext{
${ }^{46}$ Richard Post, "LLL Magnetic Fusion Research: The First 25 Years," Energy and Technology Review (April 1981): 13.

47 "Preliminary Proposal Project Sherwood Facilities Building 157 Livermore," 5.

${ }^{48}$ Black, "Sherwood," 25.

${ }^{49}$ Ibid.
}

and discovered ways to avoid them. ${ }^{50}$ In 1969, extensive modifications to the second and third floor of Building 431 were made to accommodate the superconducting Levitron experiment. ${ }^{51}$ The superconducting Levitron was installed on the south side of the third floor. Those experiments were cancelled in the early 1970 s.

\subsection{MFTF}

In 1977, Building 431 was extensively remodeled for the Mirror Fusion Test Facility (MFTF). All previous Sherwood Projects, Astron and Levitron among them, were removed from the building to make way for a very large mirror device, the MFTF. The MFTF was the latest magnetic mirror machine in the Magnetic Fusion Energy Program, previously designated Project Sherwood. It built on the advances in plasma confinement and mirror technology of the 2XIIB and Baseball II mirror machines. 2XIIB and Baseball II grew out of the first Toy Top experiments and were housed in Building 435. MFTF was planned as an intermediate step between previous mirror machines and an experimental fusion reactor. ${ }^{52}$

The old MTA concrete shielding blocks were reconfigured to house the MFTF. The vacuum vessel of the MFTF was placed in the pit and was eighteen meters in height and ten meters in diameter. The

\footnotetext{
${ }^{50}$ University of California Radiation Laboratory, Status Report: Fiscal Year 1965 (Berkeley and Livermore: University of California Radiation Laboratory, 1965), 53-54.

51 "Levitron-Experiment Modifications Second Floor Plan," PLA 1969-0431-0005D, PEL; and "Levitron-Experiment Modifications Third Floor Plan South Side," PLA 1969-0431-0006D, PEL.

${ }^{52}$ Franklin P. Dixon, "Mirror Fusion Test Facility," Energy and Technology Review (April 1981): 27.
} 
major components of the MFTF machine were the yin-yang magnet (made of copper stabilized niobium titanium superconductor) in its center, and the two yin-yang coils. ${ }^{53}$

The MFTF control room, power supplies, diagnostic areas, and other auxiliary equipment were located on the ground floor and on four mezzanines, two on each side of the vessel. ${ }^{54}$

\subsection{MFTF-B}

In 1980, the Tandem Mirror Experiment (TMX) made a significant breakthrough in plasma containment characteristics that led to the complete remodeling of the MFTF even though it was only eighty-five percent completed. The MFTF was revised from a single mirror to a tandem mirror configuration, and redesignated the Mirror Fusion Test Facility Modification B (MFTF-B). ${ }^{55}$

Almost all of the equipment used in the MFTF was incorporated into the MFTF$\mathrm{B}$, including the pulsed-power subsystem, the power subsystem for the neutral-beam-injector, the superconducting yin-yang magnets, and the cryogenic system. ${ }^{56}$ The major components of the MFTF-B were the magnet set, vacuum vessel, and neutral beam systems. In order to accommodate this larger mirror machine, Building 431 was expanded to the west side. ${ }^{57}$

The MFTF-B vessel was also housed in the pit and surrounded by the concrete

\footnotetext{
${ }^{53}$ Ibid., 29-30.

54 Ibid., 29.

55 "Energy and the Environment," Energy and

Technology Review (July 1981): 23.

${ }^{56}$ Ibid., 24.

${ }^{57}$ MFTF-B: A Tandem Mirror Fusion Test Facility, LLL-TB-O31-R1 (Washington, DC: GPO, 1986), 7.
}

shielding blocks. It was covered with a structure of pipes for nitrogen and liquid helium. The vessel system was comprised of three sections: east end vessel, west end vessel, and central cell vessel. The magnet system was the largest superconducting system in the world at the time. It had two ying-yang magnets and twenty-four superconducting coils. The magnet system and its supporting equipment weighed 1,350 tons and had to be rolled into the building on a system of logs. ${ }^{58}$

MFTF-B scientists designed the machine to operated on pure deuterium at temperature of 150 million degrees Celsius, creating a superheated plasma and containing it for a full second. ${ }^{59}$

In 1986, after six years of construction, the MFTF-B was dedicated. The next day the DOE mothballed the project due to budget restrictions. At the time it was mothballed, the MFTF-B still required diagnostic equipment and heating elements to be fully operational-a goal at least eighteen months and 250 million additional dollars away. ${ }^{60}$

The individual magnets were both tested and operated successfully at full power. However, the MFTF-B was never fully operational.

In 1998, the MFTF-B was finally dismantled. Many of the components were transferred to other laboratories or to manufacturers involved in magnetic fusion research. Other parts went to salvage.

\footnotetext{
${ }^{58}$ Ibid., 12-19.

${ }^{59}$ William Booth, "Fusion's \$372-Million Mothball," Science (October 1987): 1-4.

${ }^{60}$ Ibid.
} 


\subsection{Experimental Test Accelerator (ETA)}

In 1979, the Experimental Test Accelerator (ETA) was installed in the south wing of Building 431. The ETA was a prototype accelerator designed "to study electron beam propagation in air as a possible directed-energy weapon.. ${ }^{, 61}$ Although not associated with fusion research, the ETA built on the induction linear accelerator technology pioneered in the Astron project. Experiments with the ETA led to a much larger and more energetic accelerator, the Advanced Test Accelerator (ATA), completed in 1983, at Site 300 . The beam of the ATA was used as a driver for a free electron laser (FEL).

In 1987, a new linear induction accelerator, the ETA II, was installed in the south wing of Building $431 .^{62}$ The ETA II furthered FEL research and powered a microwave free-electron laser used to heat plasma in the Microwave Tokamak Experiment (MTX), a fusion research project also located in Building $431 .{ }^{63}$ In 1992 , the ETA II facility was shut down along with the MTX.

In 1997, LLNL re-furbished the ETA II for use as a radiographic machine in a DOE-proposed Advanced Hydrotest Facility (AHA). ${ }^{64}$ The ETA II is still

\footnotetext{
${ }^{61}$ Serving the Nation for Fifty Years, 23; and "Experimental Test Accelerator (ETA): Generation of High-Intensity Electron Beams," Technical Summary (Livermore: Lawrence Livermore Laboratory, 1981).

62 "New Linear Induction Accelerator," Energy and Technology Review (July 1987): 58-59.

63 "Microwave Tokamak Experiment," Energy and Technology Review (July 1987): 48-49.

${ }^{64}$ J. T. Weir, G. J. Caporaso, J. C. Clark, H. C. Kirbie, Y.-J. Chen, S. M. Lund, G. A. Westenskow, and A. C. Paul, ETA II Experiments for Determining Advanced Radiographic Capabilities of Induction Linacs,
}

located in the south wing of Building 431. It is being used to develop advanced radiographic capabilities for stockpile stewardship. It has produced no significant scientific breakthroughs yet. The south wing of Building 431 is not currently threatened.

\subsection{Microwave Tokamak Experiment} When DOE mothballed the MFTF-B, it also abandoned the magnetic mirror approach to fusion. Instead, LLNL redirected its Magnetic Fusion Energy program toward the tokamak concept. ${ }^{65}$

In 1987, LLNL purchased the Alcator-C tokamak, a toroidal fusion machine, from the Massachusetts Institute of Technology and installed it in Building 431. The Alcator-C tokamak was part of the MTX. The MTX used microwaves generated by a free-electron laser in the ETA II to heat the plasma in the Alcator-C tokamak to produce thermonuclear fusion. ${ }^{66}$

In 1992, the MTX scientists completed the tokamak plasma heating experiments, and the machine was dismantled. The MTX was the last active Magnetic Fusion Energy program located in Building 431.

\section{Assessment and Recommendation}

This section is an assessment of Building 431's historic significance within the four NHPA criteria. Included are an assessment of the building's integrity for the relevant periods of historic significance and a final recommendation.

UCRL-JC-126072 (Livermore: Lawrence Livermore National Laboratory, 1997), 1. 65 "Magnetic Fusion Energy," Energy and Technology Review (July 1987): 46-47. 66 "Microwave Tokamak Experiment," 48. 
As the assessment indicates, the only two periods of historic significance for Building 431 are the Toy Top experiments from 1954 to 1963 , and the breakthrough in accelerator technology in the Astron experiment from 1957 to 1973.

\subsection{Criterion A: Historic Events}

A property is associated with events that have made a significant contribution to the broad patterns of our history.

Building 431 would be considered historic under Criterion $\mathrm{A}$ if it were associated with important historical events with in the context of the Cold War and the LLNL preservation theme of Nuclear Weapons Design, sub-theme of Physics Research within the theme of Nuclear Research, or the sub-theme of Energy Research within the theme of Non-weapons Research.

Considering the programs housed within Building 431 over time highlights the specific moments of historic significance and the building's direct contribution to the Cold War. The programs are assessed here within the appropriate LLNL preservation themes and subthemes.

\section{Theme: Nuclear Weapons Design In 1950, Building 431 was built to house the Mark I accelerator, a prototype MTA accelerator designed to produce quantities of fissionable material for the development of nuclear weapons. The Mark I accelerator was the world's largest particle accelerator at the time.}

In 1952, Lawrence successfully lobbied for the establishment of a second nuclear weapons laboratory at the site of the former naval air station in Livermore largely on the strength of the MTA program in Building 431 already under his management and supervision.

In 1952, with the discovery of rich uranium deposits, the MTA program was first reduced and then cancelled the following year. Mark I, although the largest particle accelerator of its time, was dismantled before it fully achieved its technological objectives. Mark II and Mark III were never built. Therefore, the MTA program never supplied fissionable material for the nuclear weapons program and does not meet the NHPA standard of historic significance under the preservation theme of Nuclear Weapons Design.

Theme: Nuclear Research; Sub-theme: Nuclear Physics Research From 1957 to 1973, Building 431 housed the Astron project, an induction linear accelerator designed to super-heat plasma. Astron was designed and built by Nicolas Christofilos as an alternative approach to controlled thermonuclear fusion for energy. The beam of Astron was first fully powered by 1963, and the entire system was completed in 1969. The project was cancelled in 1973, a year after Christofilos's death. The Astron accelerator never fully achieved its technical objectives for heating plasma. Nevertheless, Astron proved to be a significant improvement in accelerator technology and particlebeam physics. It served as a prototype for future induction linear accelerators including the ETA, the ATA, and the ETA II. The Astron induction linear accelerator was the most energetic accelerator of its time and, therefore, was a technological and scientific breakthrough in accelerator design. 
Thus, if Building 431 reflects the development of the Astron accelerator from 1957 to 1973, it may qualify for National Register consideration within the LLNL preservation theme of Nuclear Research and the sub-theme of Nuclear Physics Research within the context of the Cold War.

Theme: Non-weapons Work;

Sub-theme: Energy Research

From 1954 to 1992 , the primary mission of all programs based in Building 431 was controlled fusion research - the creation of a fusion reaction as a source of abundant energy.

LLNL scientists pioneered the magnetic mirror approach to the problem of heating and containing plasma long enough for fusion to occur. In 1952, they constructed the first magnetic mirror machine to demonstrate the feasibility of the magnetic mirror concept, called Cucumber I. The Cucumber I experiment is considered to be one of the first breakthroughs in fusion research. ${ }^{67}$ At the time of the breakthrough, however, Cucumber I was located in Building 212; it was later relocated to Building 431.

In 1960, the Toy Top machine, then located in Building 431, succeeded in both heating and containing plasma in a mirror system. The Toy Top model was then chosen for further development. Building 431 housed several successive models of Toy Top. In 1963, Toy Top III or $2 \mathrm{X}$ required more room and was relocated to Building 435.

${ }^{67}$ Richard Post, phone interview with Michael Anne Sullivan, 3 April 2003; and Edwin Hooper, phone interview with Michael Anne Sullivan, 3 April 2003.
In 1968 , the $2 X$ machine made the next breakthrough in fusion research. The $2 \mathrm{X}$ overcame plasma instabilities by "evaporatively coating the vacuum chamber walls with a thin, clean, titanium metal surface that removed impurity atoms by surface absorption."68 The $2 \mathrm{X}$ was located in Building 435 at the time of the breakthrough.

The Toy Top models located in Building 431 from 1954 to 1963 were among the first fusion research experiments at LLNL. These experiments led to scientific breakthroughs in fusion research that occurred in the $2 \mathrm{X}$ experiment and are of historic significance. If Building 431 still reflected the Toy Top experiments of 1954-1963, then it would be eligible for the National Register for this period of historical significance.

The next program of potential historic interest, located in Building 431 from 1957 to 1972 , was Astron. Astron was an attempt to use an electron accelerator to heat and contain plasmas. The Astron project proposed a unique method of plasma containment using an E-layer of electrons moving in an orbit within the magnetic field. In 1963, Astron achieved full power for the first time. Although a unique method for plasma confinement, Astron never achieved E-layers with enough power to sustain a thermonuclear reaction. The program was terminated in 1973.

\footnotetext{
${ }^{68}$ Richard Post, "LLL Magnetic Fusion Research: The First 25 Years," Energy and Technology Review (May 1978): 7; and "A New Stability for 'Bottled' Plasmas," The Magnet (May 1968): 5.
} 
The Astron project does not represent any scientific breakthroughs in magnetic mirror technology or controlled thermonuclear research. The information gleaned from the Astron experiment represented research that led to the incremental increase of knowledge in the field of controlled thermonuclear fusion research. Therefore, Astron does not meet the threshold for historic significance within the context of the Cold War, the preservation theme of Non-Weapons Research, and the subtheme of Energy Research.

In 1975, LLNL scientists made another significant breakthrough in fusion research with the 2 XIIB machine. The 2XIIB succeeded in confining plasma through the addition of cold plasma toward the ends of the device. ${ }^{69}$ The 2XIIB, located in Building 435, was the lineal descendent of the $2 \mathrm{X}$ and Toy Top experiments.

The 2XII B experiments led to the TMX - the next generation of fusion research. In 1980, the TMX succeeded in creating a thermal barrier at the ends of the machine by heating electrons to retain the plasma. ${ }^{70}$ The TMX experiment was housed in Building 435.

The breakthroughs created in the TMX led to the magnetic mirror design used in the construction of the MFTF and the MFTF-B. These magnetic mirror machines had the largest superconducting magnets in the world when they were completed in 1980 and 1986, respectively. Nevertheless, neither

${ }^{69}$ Richard Post, phone interview with Michael Anne Sullivan, 3 April 2003; and Edwin Hooper, phone interview with Michael Anne Sullivan, 3 April 2003.

${ }^{70}$ Ibid. the MFTF nor the MFTF-B is eligible for the National Register. Neither machine was ever fully operational or met its scientific goals of plasma containment. The scientific breakthrough that led to the MFTF-B during the TMX experiment did not occur in Building 431.

In conclusion, no fusion research experiment that occurred in Building 431 represents an event of historical significance with the exception of the Toy Top machines that were present in the building from 1954 to 1963 . At this time, it appears that all other experiments and research machines for achieving fusion that were housed in Building 431 represent interesting but not breakthrough scientific activities within the field of fusion research. The experiments that did represent breakthroughs in controlled thermonuclear fusion did not occur in Building 431.

In 1986, the Magnetic Fusion Energy research program at LLNL was terminated along with the MFTF-B. If controlled thermonuclear fusion by means of either a pinch or magnetic mirror process is finally realized in the future, then earlier experiments in Building 431 may be of historic interest. However, it is unlikely they will cause Building 431 to be eligible for the National Register, as it has long since been stripped of the machines with which the work was done.

\subsection{Criterion B: Historic Person}

A property is associated with the lives of persons significant in our past.

Building 431 is associated with several people of recognized historical 
significance. Ernest O. Lawrence, the creator and first director of UCRL, has been recognized by the historical profession as a scientist and politician of national significance. Lawrence invented the first cyclotron at Berkeley, participated in and defined many of the processes for fissile material production for the Manhattan Project during WWII, and continued to be an active force in the development of the nuclear weapons stockpile and high-energy physics research after the war.

In 1950, Lawrence developed the MTA research project and persuaded the AEC to fund it. Building 431 is directly associated with the MTA and Lawrence. However, to be considered eligible for the National Register under Criterion B, a structure must be the primary location of the historic person's work or the location of an important event involving that person. Although Lawrence was responsible for the creation of the MTA and visited the site on occasion, Building 431 was neither his primary work place nor the location of any of his scientific discoveries. Therefore, it does not qualify for National Register consideration under Criterion B with regard to Lawrence.

Building 431 is also associated with other physicists who are among the top scientists in the field of fusion research. Richard Post conceived of and ran the magnetic mirror effort at LLNL from 1952 until 1986. From 1953 to 1973, Nicolas Christofilos designed and ran the Astron program. From 1952 to 1963, Sterling Colgate ran the pinch program at LLNL. When he resigned, Donald Furth headed the program until its demise in the 1970s. Kenneth Fowler led the tandem mirror program and the
MFTF-B project from 1977 to 1986. These men are recognized as among the leading physicists in their field by both their colleagues and historians.

Nevertheless, Building 431 is not eligible for National Register consideration under Criterion B. The field of fusion energy research is still quite young and in such a state of flux that it is impossible at this time to know if any of the projects that these men headed will prove out in a final, successful conversion of fusion to energy. Also, although these men did work in this building, it was not the primary location of their working lives. Much of their work was theoretical in nature and took place in their offices, which were located elsewhere.

\subsection{Criterion C: Architectural Design/Construction}

A property embodies the distinctive characteristics of a type, period, or method of construction, or that represent the work of a master, or that possess high artistic values, or that represent a significant and distinguishable entity whose components may lack individual distinction.

Building 431 does not represent the distinctive characteristics of a type, period, or method of construction. Building 431 is of industrial vernacular design. It is a large structure built to shelter scientific research equipment. It is not distinctive in its exterior appearance or design. Its interior is an uninteresting framework for the research programs it once housed. The design element of the most potential interest is the concrete shielding for the accelerator pit. However, the shielding consists of poured concrete blocks frequently 
relocated and modified in layout that, without the operations they once shielded, are not representative of any creative or interesting effort.

\subsection{Criterion D: Information Potential}

The property yields, or may be likely to yield, important information in prehistory or history.

Building 431 does not now yield, nor is it likely in the future to yield, important pre-historical or historical information. It is of the historic period and indicates nothing of the pre-historic. Without the research equipment it once housed, it does not tell us anything about the history of that scientific endeavor.

Building 431 does not provide the historic record with any information that is not available elsewhere. The research regarding Building 431's history turned up voluminous written documentation. There are numerous reports available about the work that went on in Building 431. There is also a comprehensive record of the building's construction and modifications.

\subsection{Integrity}

Building 431 qualifies for National Register consideration for the 1954 to 1963 period for its scientific breakthroughs in magnetic mirror plasma confinement in the Toy Top machines. It also qualifies for National Register consideration for the 1957 to 1973 period for its technological breakthrough in accelerator technology in the Astron program.

In 1952, Toy Top moved into Building 431 and occupied several laboratories on the north side of the third floor. These laboratory spaces still exist within
Building 431. However, the breakthroughs associated with the Toy Top machines were reflected only in the machines and not in the actual laboratory space. Toy Top could have been housed in any laboratory space of approximately the same size. Furthermore, the rooms used for the Toy Top machines have long been stripped of any equipment that represented the breakthrough in plasma science that occurred in this building. Since 1963, these rooms have housed a variety of equipment associated with other magnetic mirror experiments - the Levitron, Astron, MFTF, and MFTF-B.

However, Building 431 did more directly reflect the Astron experiment. The main chamber of the Astron machine was located within the northern portion of the original MTA pit and surrounded by the MTA concrete shielding blocks, although in an altered configuration. A control room and proton tank were located outside the pit area in the south and north corners of the first floor, respectively. In 1967 and 1969, two new increments were added to the south side of the building to accommodate the Astron accelerator, adding approximately 12,000 square feet to the original building. The former Toy Top laboratories were used as additional laboratory space for the project. Figures 4 and 5 show the original configuration of the MTA shielding blocks and the altered layout of the Astron experiment.

The accelerator addition to Building 431 does still look, from the exterior, much as it did when it housed Astron.

However, the interior of Building 431 more clearly reflected Astron's mission and it has been significantly altered since the program's demise in 1973. 
In 1977, the shielding blocks of the Astron main chamber were reconfigured, from an L-shape to a square, to accommodate the MFTF experiment. In 1981, eighty feet was added to the west end of the building on all levels substantially increasing the footprint of the original building. The pit doubled in size and the shielding blocks were reconfigured yet again. To seismically strengthen the building, concrete was poured over the shielding blocks on the west side of the pit. In 1998, the MFTF$\mathrm{B}$ was dismantled leaving behind the shielding blocks and little else. Although the concrete shielding blocks used for the Astron experiment still remain in the building, they no longer reflect that experiment.

The south wing of Building 431, added for Astron, has also been substantially altered. In 1979, the ETA accelerator was installed where the Astron accelerator was previously located. In 1987, the ETA accelerator was removed and the ETA II installed. The ETA II was used to heat plasma in the MTX, a tokamak fusion machine installed outside the MFTF-B shielding wall. The MTX was removed in 1992. In 1997, the ETA II was refurbished and the corridor that formerly connected the Astron accelerator to the main building sealed off. Although accelerator work still is conducted in the south wing of Building 431, it no longer reflects the Astron accelerator in any way.

In conclusion, Building 431 no longer possesses historical integrity for either of the periods of its historic significance. Furthermore, with the exception of the ETA II, the building does not reflect any of the work that occurred there. The building was repeatedly upgraded and renovated from 1950, when it was first built for the MTA, until 1987, when the MTX was installed after the demise of the MFTF-B. Furthermore, the equipment that might have represented the fusion or accelerator research in this building has been removed. Only the concrete shielding, the control room for the MTX, and some of the cryogenic system for the MFTF-B remain in the building. Building 431 is largely an empty shell and no longer represents any of its missions.

\subsection{Recommendation}

Building 431 is not eligible for the National Register of Historic Places. Assessed under the four criteria for eligibility, it would qualify only under Criterion A within the LLNL preservation sub-theme of Energy Research under the theme of Nonweapons Research. However, the building lacks integrity for the relevant period of significance.

Should the building still be in place in twenty years, it will require a new assessment, as further distance in time may transform the understanding of more recent activities in the building.

ETA II, located in the south wing of the building, is of no historic interest at this time. It is also not currently threatened. If it faces an undertaking in the future, consideration should be given to whether it has experienced or contributed to any significant scientific breakthroughs at that time. If it has, a full assessment will be required. 


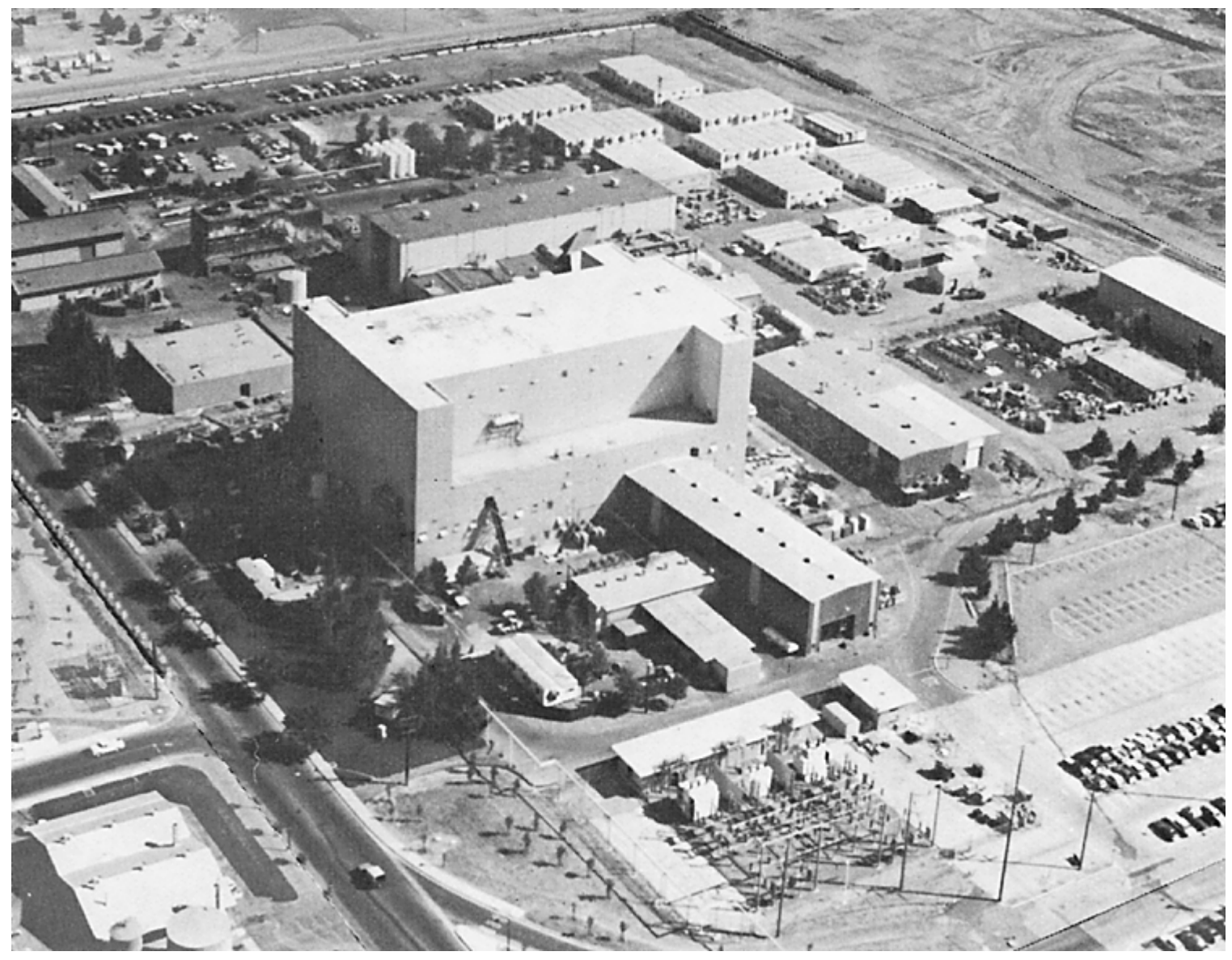

Figure 1. Aerial view of Building 431 exterior looking northeast ${ }^{1}$

1 "Magnetic Fusion Energy Program," technical summary (Livermore: Lawrence Livermore National Laboratory, 1981) 


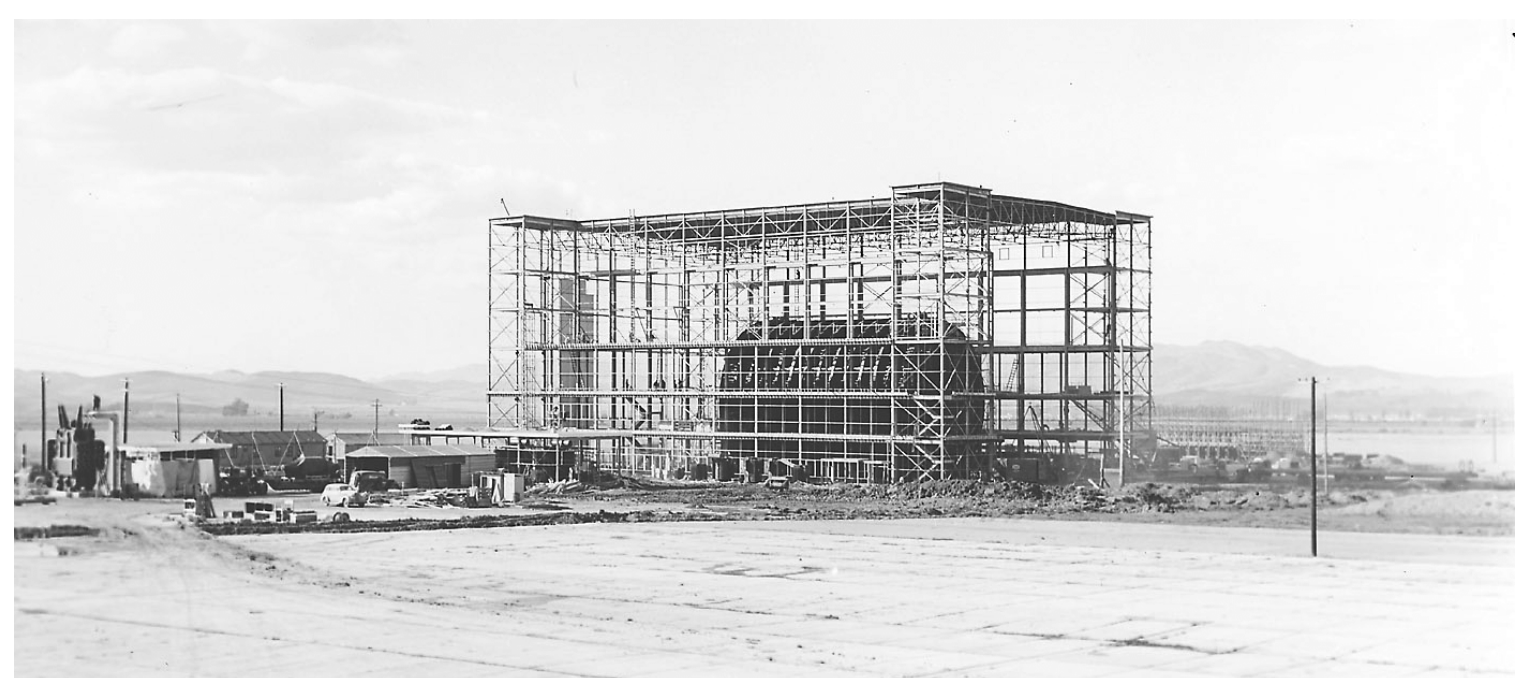

Figure 2. MTA vacuum vessel, Building $431^{2}$

\footnotetext{
${ }^{2}$ LLNL Archives.
} 


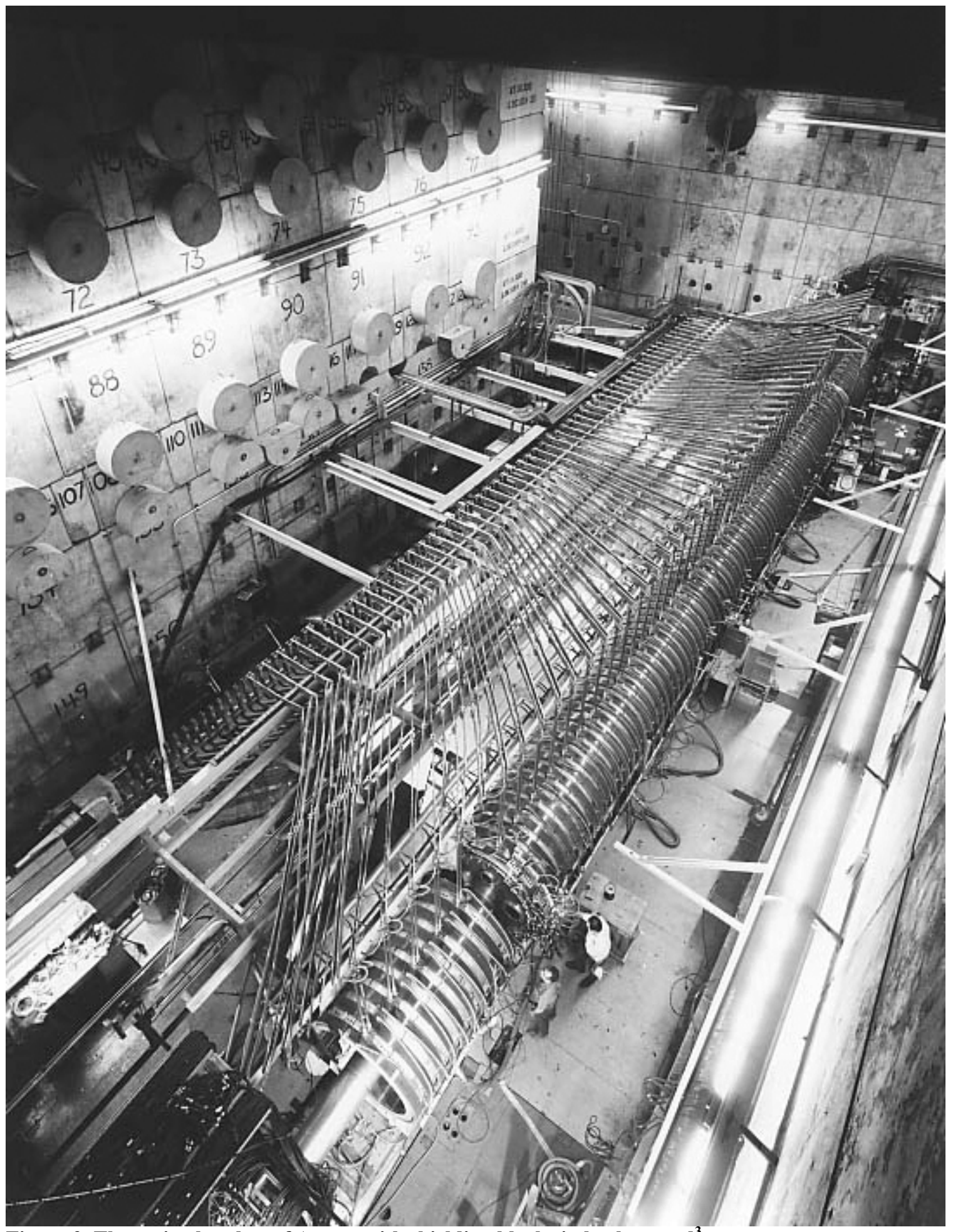

Figure 3. The main chamber of Astron with shielding blocks in background ${ }^{3}$

${ }^{3}$ LLNL Archives. 


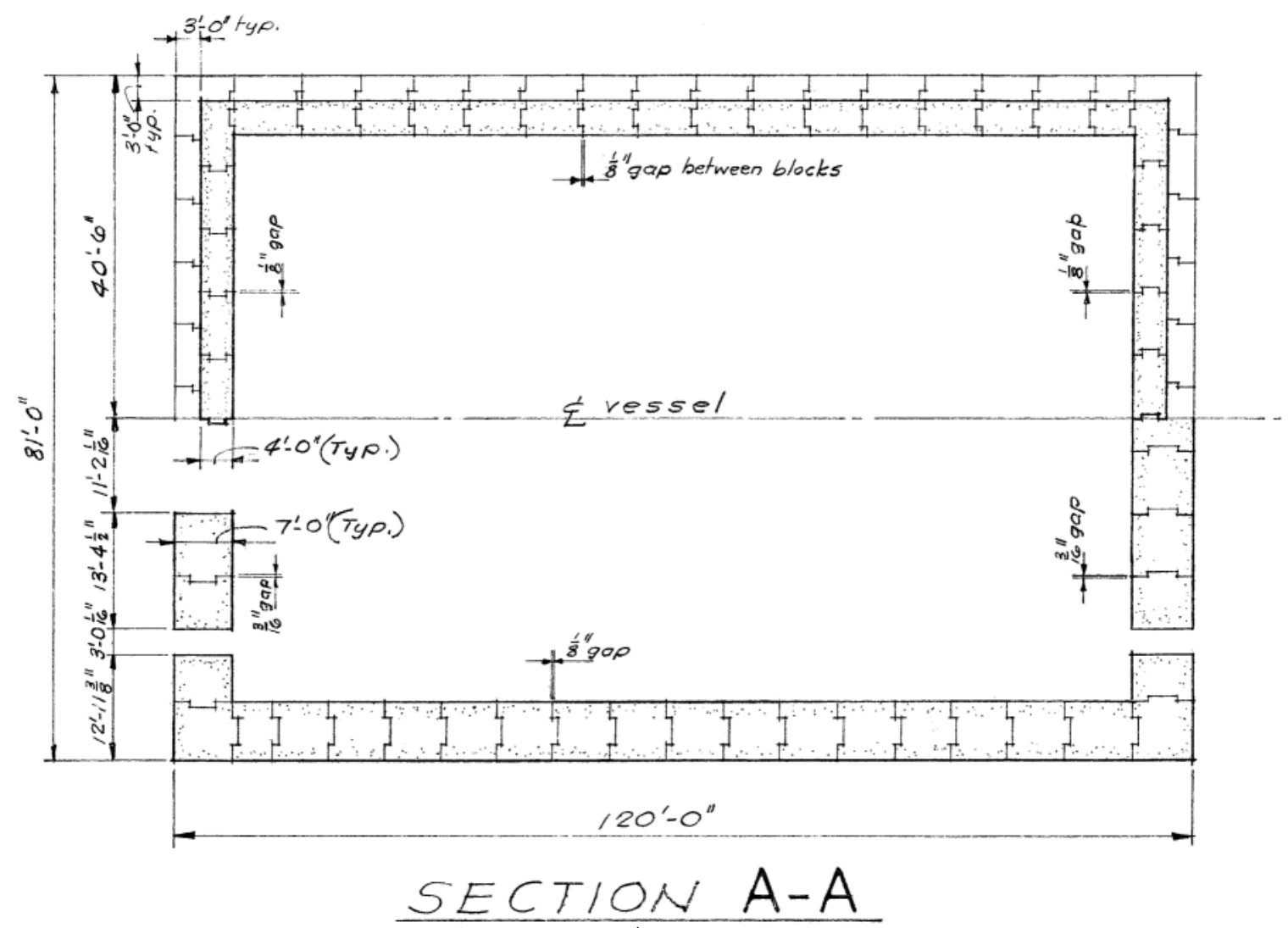

Figure 4. Original layout of MTA shielding blocks ${ }^{4}$

\footnotetext{
4 "Erection Diagram and Bolting Details, Accelerator Shielding, Accelerator Building, Plant \#3, Project X-
} 1," PLR 51-157-047JF, PEL. 


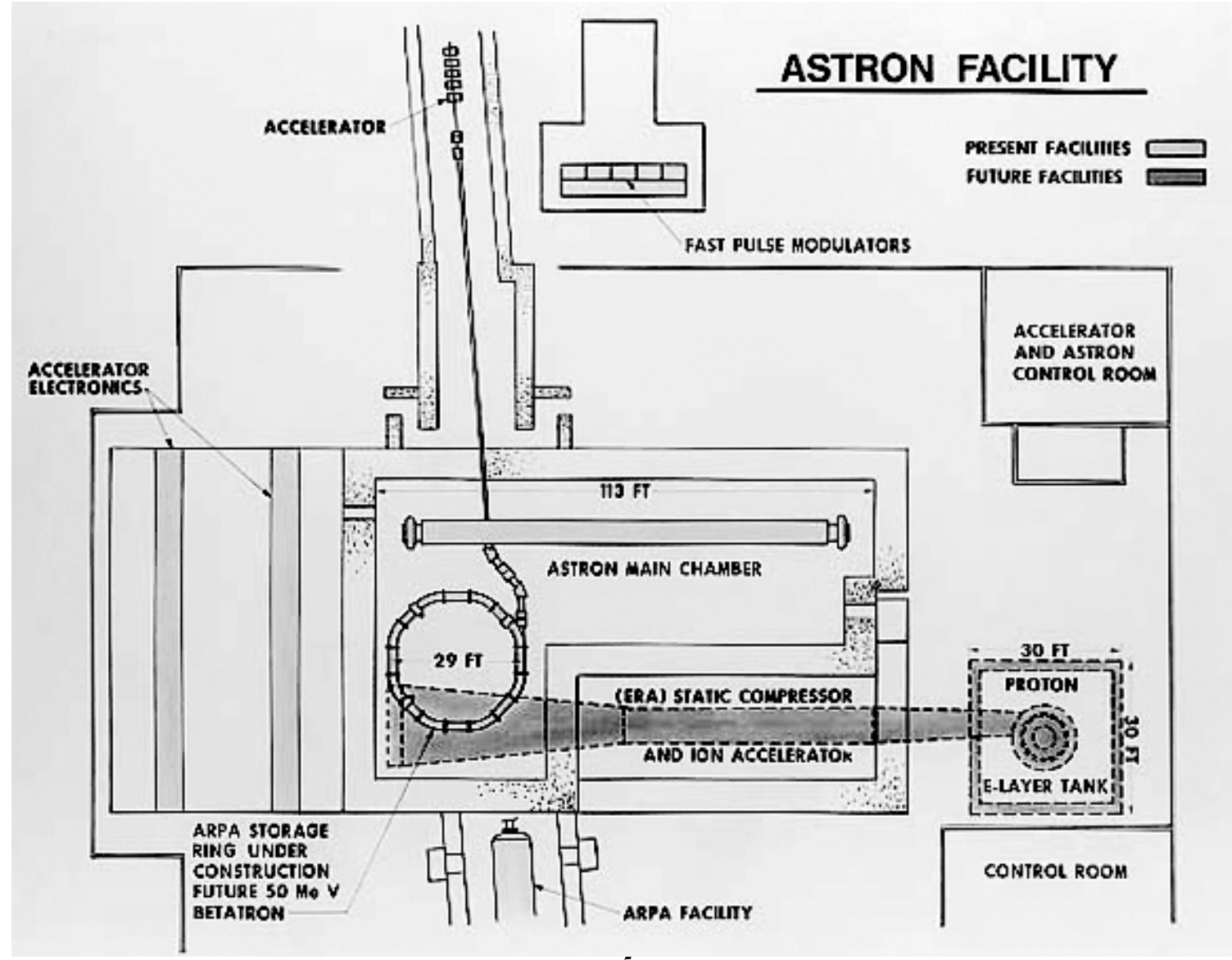

Figure 5. The floor plan for the Astron experiment. ${ }^{5}$

${ }^{5}$ LLNL, Archives. 